Announc. 2017;5:e01630-16. http://dx.doi.org/10.1128/ genomeA.01630-16

9. Wylie TN, Wylie KM, Buller RS, Cannella M, Storch GA. Development and evaluation of an enterovirus D68 real-time reverse transcriptase polymerase chain reaction (RT-PCR) assay. J Clin Microbiol. 2015;53:2641-7. http://dx.doi.org/10.1128/ JCM.00923-15

Address for correspondence: Mythili Srinivasan, Washington University School of Medicine, St. Louis Children's Hospital, Department of Pediatrics, One Children's Place, NWT 9113, St. Louis, MO 63110, USA; email: srinivasan_m@kids.wustl.edu

\section{Adenovirus-Associated Influenza-Like Illness among College Students, Pennsylvania, USA}

\section{Holly M. Biggs, Xiaoyan Lu, Lisa Dettinger, Senthilkumar Sakthivel, John T. Watson, Sameh W. Boktor}

\begin{abstract}
Author affiliations: Centers for Disease Control and Prevention, Atlanta, Georgia, USA (H.M. Biggs, X. Lu, J.T. Watson); Pennsylvania Department of Health, Harrisburg, Pennsylvania, USA (L. Dettinger, S. Boktor); Batelle, Atlanta (S. Sakthivel)
\end{abstract}

DOI: https://doi.org/10.3201/eid2411.180488

Among students with influenza-like illness at a Pennsylvania college student health center during 2016-2017, 44 $(15 \%)$ of 288 with respiratory specimens tested positive for human adenovirus (HAdV). HAdV-3, -7 , and -4 predominated, and types clustered temporally. HAdV infection should be considered among college students with acute respiratory illness.

$\mathrm{H}$ uman adenoviruses (HAdVs) cause a range of clinical manifestations, most commonly acute respiratory illness (ARI), gastroenteritis, and conjunctivitis. Seven HAdV species $(A-G)$ and $>80$ types are known to cause human infection, and certain HAdV types are associated with particular tissue tropisms and clinical syndromes (1). Outbreaks of HAdV infection occur in a variety of settings, including schools, long-term care facilities, military recruit training facilities, and the civilian community (2-4). The substantial impact of HAdV ARI among US military recruits drove development of the first live oral vaccine for HAdV types 4 and 7 for military use. After vaccine introduction in 1971, and again after reintroduction in 2011, dramatic declines were documented in respiratory illness among recruits (5). Currently, the HAdV vaccine for types 4 and 7 is licensed in the United States for use in military personnel $17-50$ years of age and is administered routinely at all US basic military training sites (5). However, despite some similarities between military recruits and civilian college students, including age and sharing of residences, little is known about the contribution of HAdV to respiratory illness in college students.

The Pennsylvania Department of Health (PDH) conducts surveillance for influenza-like illness (ILI), defined as fever (temperature $\geq 100^{\circ} \mathrm{F}\left[\geq 37.8^{\circ} \mathrm{C}\right]$ ) plus cough or sore throat without a known cause other than influenza, at participating outpatient healthcare facilities throughout the state. Basic demographic information is recorded, and from a convenience sample of cases, a nasopharyngeal swab specimen is collected. These specimens are tested by the PDH Bureau of Laboratories using Centers for Disease Control and Prevention (CDC) real-time reverse transcription PCR for influenza A and B, HAdV, respiratory syncytial virus, human metapneumovirus, rhinovirus, and parainfluenza virus types $1-3$.

We describe HAdV types associated with ILI among students who sought care at a student health center (SHC) on a large college campus during August 28, 2016-August 26, 2017. Specimens identified as HAdV-positive among students with ILI at the SHC were sent to CDC to determine HAdV species and type. Molecular typing was performed by PCR and sequencing of the hexon hypervariable regions $1-6(6)$.

During the study period, 1,149 ILI cases were reported from the SHC; for 288 (25\%), a nasopharyngeal swab specimen was tested for respiratory viruses (Figure, panel A). Of these, $44(15 \%)$ specimens were positive for HAdV. Three HAdV species and 4 HAdV types were detected: HAdV-3 and HAdV-7 of species HAdV-B in 21 (48\%) and $16(36 \%)$, respectively; HAdV-4 of species HAdV-E in 5 (11\%); and HAdV-1 of species HAdV-C in $2(5 \%)$. The median age of HAdV-positive students was 19 years (range 18-27 years), and 31 (70\%) were male. Among HAdVpositive specimens, rhinovirus was co-detected in 4 and parainfluenza virus type 2 in 1 .

HAdV-3 was identified during September-December; no additional HAdV-3 was identified after the 4-week winter break. HAdV-7 and -4 were first detected in December, before winter break, then throughout the spring; HAdV-7 was the most commonly detected type during this period (Figure, panel B). 


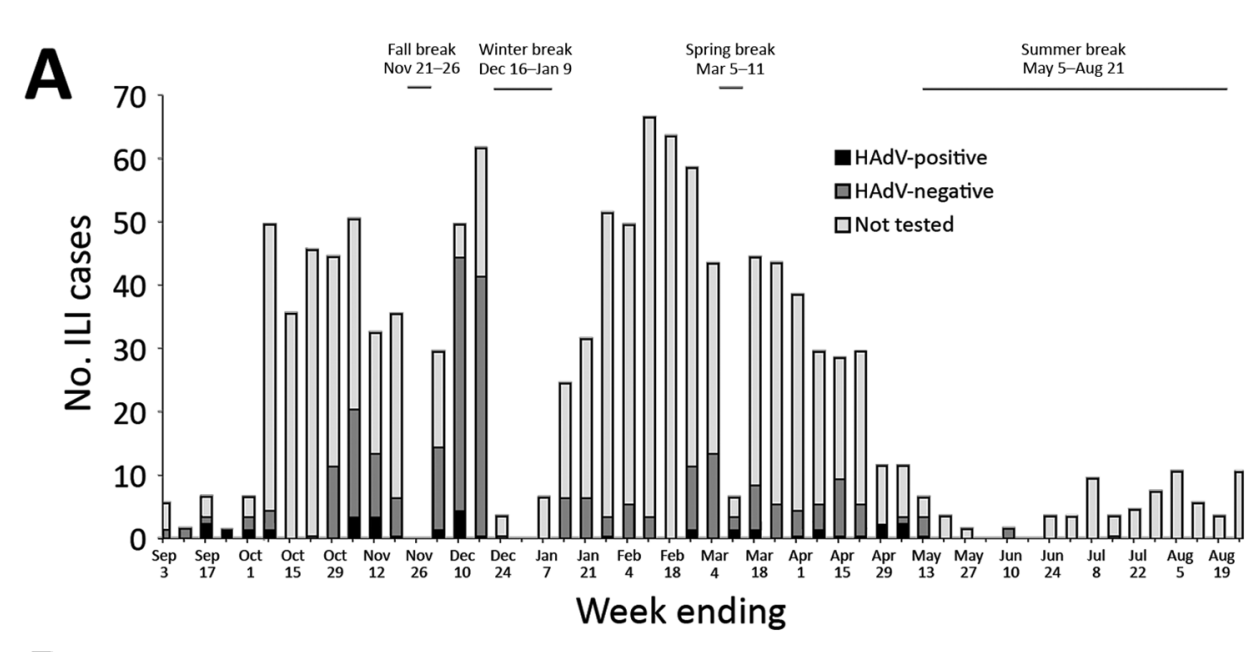

Figure. Adenovirus-associated ILI among students at a state college, Pennsylvania, USA, August 28, 2016-August 26, 2017. A) ILI cases from the student health center (SHC) and weekly number of human adenovirus (HAdV)-positive, -negative, and not tested cases. B) HAdV types identified from the SHC. HAdV detections were aggregated by epidemiologic week based on specimen collection date. Fall semester 2016 began August 22, 2016; spring semester 2017 ended May 5, 2017; fall semester 2017 began August 21, 2017. ILI, influenza-like illness.

B

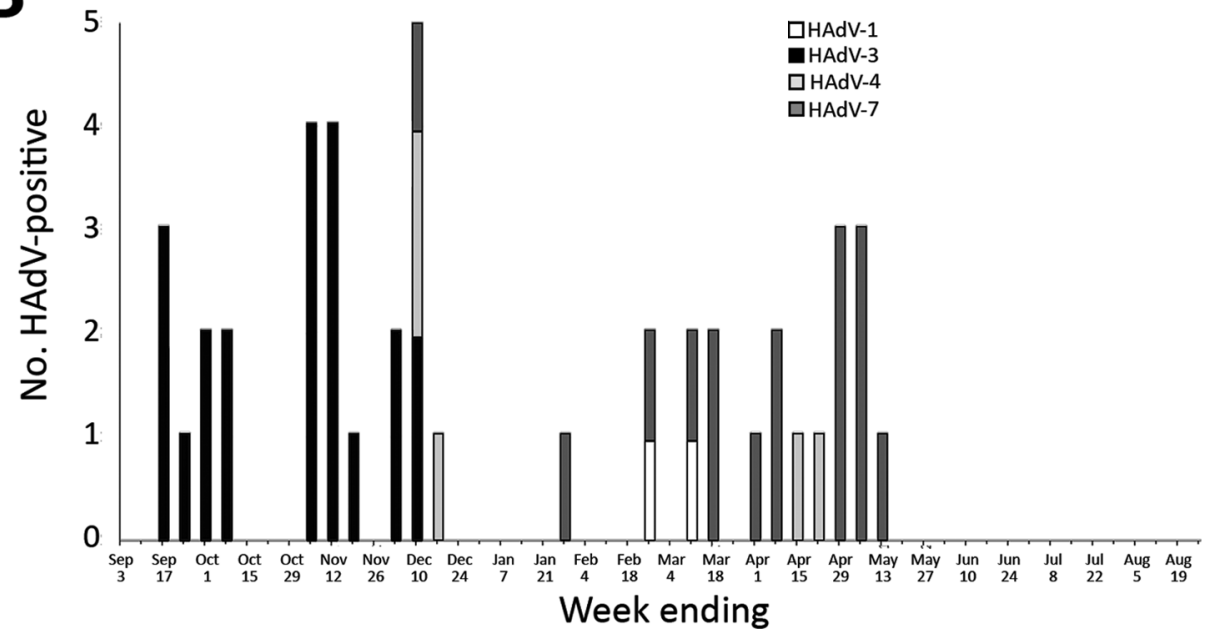

The HAdV types detected from the SHC are recognized causes of ARI. HAdV-3 was the most commonly reported HAdV type in the United States during 2003-2013 (7). HAdV-4 and -7 are increasingly recognized as causes of respiratory illness in the community and other nonmilitary populations (7-9); HAdV-7, in particular, has been associated with severe respiratory illness in adults. A male predominance was observed among HAdV-positive students at the SHC; this finding has been previously described, but its significance is unknown $(2,4)$.

HAdVs circulate throughout the year without a discernable seasonality, although some reports describe a winter and spring predominance of respiratory outbreaks (1). The temporal clustering of types that we observed might reflect transmission dynamics within the college population rather than viral seasonal patterns per se; however, additional surveillance may help further define circulation patterns of HAdV types (8). In a comparable report from New York, during the 2014-15 influenza season, $\approx 8 \%$ of samples tested from students with ILI at 1 college were positive for HAdV; HAdV-14 and -4 were most frequently detected (10).

Our findings are subject to several limitations. Specimens tested for respiratory viruses represent a convenience sample of ILI cases, and the proportion sampled varied by week. We report findings from surveillance at a single college SHC; phylogenetic analysis of hexon sequences was not conducted, preventing comparisons between the detected virus strains and those reported to circulate in military or other civilian communities.

Although recruits at basic military training are recognized to be at risk for infection with HAdV, less is known about the risk for HAdV in nonmilitary congregate settings. We detected HAdV in a substantial proportion of ILI cases among a convenience sample of young adults at an SHC surveillance site at a large university during the 2016-17 academic year. Understanding the effects of HAdV respiratory illness on college campuses, including severity, missed class time, and occurrence of outbreaks, would be useful in assessing potential control measures in these settings. 


\section{Acknowledgments}

We thank the Pennsylvania College SHCs that participated in the Influenza-like Illness Surveillance Network (ILINet) during 2016-2017.

Specimen testing at the PDH was partially supported by CDC's Epidemiology and Laboratory Capacity for Infectious Diseases, cooperative agreement NU50CK000375.

\section{About the Author}

Dr. Biggs is a medical epidemiologist with the Division of Viral Diseases, National Center for Immunization and Respiratory Diseases, CDC. Her interests include respiratory virus surveillance and outbreak response.

\section{References}

1. Lion T. Adenovirus infections in immunocompetent and immunocompromised patients. Clin Microbiol Rev. 2014;27: 441-62. PubMed http://dx.doi.org/10.1128/CMR.00116-13

2. Centers for Disease Control and Prevention. Civilian outbreak of adenovirus acute respiratory disease - South Dakota, 1997. MMWR Morb Mortal Wkly Rep. 1998;47:567-70.

3. Kandel R, Srinivasan A, D'Agata EM, Lu X, Erdman D, Jhung M. Outbreak of adenovirus type 4 infection in a long-term care facility for the elderly. Infect Control Hosp Epidemiol. 2010;31:755-7. PubMed http://dx.doi.org/10.1086/653612

4. Lewis PF, Schmidt MA, Lu X, Erdman DD, Campbell M, Thomas A, et al. A community-based outbreak of severe respiratory illness caused by human adenovirus serotype 14 . J Infect Dis. 2009;199:1427-34. PubMed http://dx.doi.org/ $10.1086 / 598521$

5. Radin JM, Hawksworth AW, Blair PJ, Faix DJ, Raman R, Russell KL, et al. Dramatic decline of respiratory illness among US military recruits after the renewed use of adenovirus vaccines. Clin Infect Dis. 2014;59:962-8. PubMed http://dx.doi.org/ 10.1093/cid/ciu507

6. Lu X, Erdman DD. Molecular typing of human adenoviruses by PCR and sequencing of a partial region of the hexon gene. Arch Virol. 2006;151:1587-602. PubMed http://dx.doi.org/10.1007/ s00705-005-0722-7

7. Binder AM, Biggs HM, Haynes AK, Chommanard C, Lu X, Erdman DD, et al. Human adenovirus surveillance-United States, 2003-2016. MMWR Morb Mortal Wkly Rep. 2017;66:1039-42. PubMed http://dx.doi.org/10.15585/mmwr.mm6639a2

8. Scott MK, Chommanard C, Lu X, Appelgate D, Grenz L, Schneider E, et al. Human adenovirus associated with severe respiratory infection, Oregon, USA, 2013-2014. Emerg Infect Dis. 2016;22:1044-51. PubMed http://dx.doi.org/10.3201/ eid2206.151898

9. Kajon AE, Lamson DM, Bair CR, Lu X, Landry ML, Menegus M, et al. Adenovirus type 4 respiratory infections among civilian adults, northeastern United States, 2011-2015. Emerg Infect Dis. 2018;24:201-9. PubMed http://dx.doi.org/10.3201/eid2402.171407

10. Lamson DM, Kajon A, Shudt M, Girouard G, St George K. Detection and genetic characterization of adenovirus type 14 strain in students with influenza-like illness, New York, USA, 2014-2015. Emerg Infect Dis. 2017;23:1194-7. http://dx.doi.org/ 10.3201/eid2307.161730

Address for correspondence: Holly M. Biggs, Centers for Disease Control and Prevention, 1600 Clifton Rd NE, Mailstop A34, Atlanta, GA 30329-4027, USA; email: hbiggs@cdc.gov

\section{Investigating the Role of Easter Island in Migration of Zika Virus from South Pacific to Americas}

\author{
Edson Delatorre, Jorge Fernández, Gonzalo Bello
}

Author affiliations: Instituto Oswaldo Cruz/Fiocruz, Rio de Janeiro, Brazil (E. Delatorre, G. Bello); Public Health Institute of Chile, Santiago, Chile (J. Fernández)

DOI: https://doi.org/10.3201/eid2411.180586

The role of Easter Island in the dissemination of Zika virus from the Pacific islands into the Americas remains unclear. We analyzed new Zika virus sequences from Eastern Island and found that Zika virus was independently disseminated from French Polynesia into the Americas and Easter Island at around the same time.

$\mathrm{Z}$ ika virus is a mosquitoborne flavivirus associated with several recent outbreaks in human populations in the Pacific region and the Americas. Phylogeographic studies indicate that Zika virus strains circulating in South Pacific islands and Latin America comprise a single lineage $\left(\mathrm{ZIKV}_{\text {SP-AM }}\right)$ that arose because of sequential single viral disseminations from Southeast Asia into French Polynesia and from the South Pacific into Latin America (1-5). However, whether the ancestral Zika virus strain introduced into the Americas arose directly from French Polynesia or from another South Pacific island is unclear.

In early 2014, a Zika virus outbreak occurred in Easter Island (6), months before the first identification of Zika virus in Brazil (7). Easter Island is located at the southeastern edge of the Polynesian Triangle, roughly equidistant from French Polynesia and the South America mainland. Geographic position and intense touristic activity make Easter Island a potential staging post in the spread of Zika virus from French Polynesia to continental America. This hypothesis was suggested previously (4), but the study used a limited sequence dataset. We tested this hypothesis by using a more comprehensive dataset of Zika virus sequences from the South Pacific.

Blood samples from suspected Zika virus-infected human patients who visited the emergency unit of Hanga Roa Hospital on Easter Island during January-May 2014 were sent to the Public Health Institute of Chile for characterization, according to Ministry of Health of Chile guidelines for surveillance of transmissible diseases. The complete $\mathrm{E}$ and partial NS5 genes of 7 Zika virus strains were obtained as previously described (6). The concatenated fragments were aligned with Zika virus Asian genotype sequences available in GenBank and used for spatiotemporal viral diffusion 